\title{
Practice guideline update summary: Mild cognitive impairment
}

\section{Report of the Guideline Development, Dissemination, and Implementation Subcommittee of the American Academy of Neurology}

Ronald C. Petersen, MD, PhD, Oscar Lopez, MD, Melissa J. Armstrong, MD, MSc, Thomas S.D. Getchius, Mary Ganguli, MD, MPH, David Gloss, MD, MPH\&TM, Gary S. Gronseth, MD, Daniel Marson, JD, PhD, Tamara Pringsheim, MD, Gregory S. Day, MD, MSc, Mark Sager, MD, James Stevens, MD, and Alexander Rae-Grant, MD

Neurology ${ }^{\circledR}$ 2018;90:126-135. doi:10.1212/WNL.0000000000004826

\section{Abstract}

\section{Objective}

To update the 2001 American Academy of Neurology (AAN) guideline on mild cognitive impairment (MCI).

\section{Methods}

The guideline panel systematically reviewed MCI prevalence, prognosis, and treatment articles according to AAN evidence classification criteria, and based recommendations on evidence and modified Delphi consensus.

\section{Results}

MCI prevalence was 6.7\% for ages 60-64, 8.4\% for 65-69, 10.1\% for 70-74, 14.8\% for 75-79, and $25.2 \%$ for $80-84$. Cumulative dementia incidence was $14.9 \%$ in individuals with MCI older than age 65 years followed for 2 years. No high-quality evidence exists to support pharmacologic treatments for MCI. In patients with MCI, exercise training (6 months) is likely to improve cognitive measures and cognitive training may improve cognitive measures.

\section{Major recommendations}

Clinicians should assess for MCI with validated tools in appropriate scenarios (Level B). Clinicians should evaluate patients with MCI for modifiable risk factors, assess for functional impairment, and assess for and treat behavioral/neuropsychiatric symptoms (Level B). Clinicians should monitor cognitive status of patients with MCI over time (Level B). Cognitively impairing medications should be discontinued where possible and behavioral symptoms treated (Level B). Clinicians may choose not to offer cholinesterase inhibitors (Level B); if offering, they must first discuss lack of evidence (Level A). Clinicians should recommend regular exercise (Level B). Clinicians may recommend cognitive training (Level C). Clinicians should discuss diagnosis, prognosis, long-term planning, and the lack of effective medicine options (Level B), and may discuss biomarker research with patients with MCI and families (Level C).

\author{
Correspondence \\ American Academy of \\ Neurology \\ guidelines@aan.com
}

MORE ONLINE

\section{- Podcast}

Dr. Jeff Burns talks with

Dr. Ronald Petersen about the updated AAN guideline on mild cognitive impairment. NPub.org/ojn0w9 


\section{Glossary}

AAN = American Academy of Neurology; $\mathbf{A D}=$ Alzheimer disease $;$ aMCI = amnestic mild cognitive impairment; $\mathbf{C I}=$ confidence interval; CIND = cognitively impaired, no dementia; FDA = Food and Drug Administration; IADL = instrumental activities of daily living; $\mathbf{M C I}=$ mild cognitive impairment; $\mathbf{R R}=$ relative risk.

Mild cognitive impairment (MCI) is a condition in which individuals demonstrate cognitive impairment with minimal impairment of instrumental activities of daily living (IADL). ${ }^{1-3}$ Although MCI can be the first cognitive expression of Alzheimer disease $(\mathrm{AD})$, it can also be secondary to other disease processes (i.e., other neurologic, neurodegenerative, systemic, or psychiatric disorders). ${ }^{4}$ The term amnestic MCI (aMCI) describes a syndrome in which memory dysfunction predominates; in nonamnestic MCI, impairment of other cognitive features (e.g., language, visuospatial, executive) is more prominent. $^{2}$

This practice guideline updates a 2001 American Academy of Neurology (AAN) practice parameter with recommendations concerning the diagnosis and treatment of $\mathrm{MCI} .^{5}$ The guideline focuses on presumed idiopathic or neurodegenerative $\mathrm{MCI}$ - particularly relating to $\mathrm{AD}$ — rather than mild cognitive changes relating to potentially reversible causes (e.g., metabolic, vascular, systemic, or psychiatric disorders) or Parkinson disease-MCI or vascular cognitive impairment, as these may have different epidemiologic and treatment spectra than $\mathrm{AD}$. This article summarizes the guideline findings, conclusions, and recommendations. The full text of the guideline, including appendices e-1 through e-8, is available as supplemental data (links.lww. com/WNL/A125), as are tables e-1 through e-3 (links.lww.com/ $\mathrm{WNL} / \mathrm{A} 34)$ and references e1-e50 (links.lww.com/WNL/A50).

The guideline addresses 4 questions:

1. What is the prevalence of $\mathrm{MCI}$ in the general population?

2. What is the prognosis for patients diagnosed with $\mathrm{MCI}$ for progression to a diagnosis of dementia, and how does this compare with an age-matched general population?

3. What pharmacologic treatments are effective for patients diagnosed with MCI?

4. What nonpharmacologic treatments are effective for patients diagnosed with $\mathrm{MCI}$ ?

This guideline does not review the rapidly evolving field of biomarker research in MCI; the guideline panel determined that this should be the subject of a future guideline or systematic review. In addition, the potential psychological distress of a diagnosis of $\mathrm{MCI}$ (which has been discussed in the literature) was not one of the questions reviewed by the expert panel for this guideline. ${ }^{6}$

\section{$\oplus$ Supplemental Data}

Full text of guideline at:

NPub.org/4evlhy

\section{Description of the analytic process}

This practice guideline principally follows the methodologies described in the 2004 edition of the AAN's guideline development process manual. ${ }^{7}$ Conclusions and recommendations were developed in accordance with the process outlined in the 2011 guideline development process manual, as amended to include the updated scheme for classifying therapeutic articles. ${ }^{8}$ The complete guideline provides a description of the exact methodology followed, including the processes of convening the author panel, performing the literature search, and reviewing the evidence. In accordance with the 2011 guideline manual, recommendations were based not only on the evidence in the systematic review, but also on strong related evidence, established principles of care, and inferences. The level of obligation for each recommendation was based on the strength of these premises and the risk-benefit ratio of following the recommendation, with adjustments based on importance of outcomes, variation in patient preferences, feasibility/availability, and patient costs. Consensus was determined by a modified Delphi voting process in accordance with prespecified rules. ${ }^{8}$

The panelists noted that various definitions of MCI and of related terms, such as cognitively impaired, no dementia (CIND), were used in the reviewed literature. Variation was based on different ascertainment methods, different neuropsychological measures, different measure thresholds, and requirements for different cognitive deficits. There was also variation in the use of aMCI and nonamnestic MCI in these studies. To address these discrepancies, the panelists reflected the specific definition used for a study where feasible in the evidence synthesis tables and guideline text, and provided specific comments on the potential effect of differing definitions.

\section{Analysis of evidence}

\section{What is the prevalence of $\mathrm{MCl}$ in the general population?}

\section{Background}

Various definitions of MCI have been used over time, reflecting an evolution of thought from primarily focusing on amnesia to including other cognitive deficits. Because memory deficits are the clinical hallmark of $\mathrm{AD}$, some groups used criteria for $\mathrm{MCI}$ that required the presence of memory deficits in isolation (e.g., aMCI), ${ }^{3,9,10}$ and others included a broader definition that included either single-domain 
nonamnestic deficits or deficits in multiple cognitive domains, either with memory impairment (multidomain aMCI) or without (multidomain nonamnestic MCI). ${ }^{1,2,11}$ The definition of MCI is also affected by the psychometric properties of, and norms for, the tests used to identify thresholds between normal aging and MCI. Table e-1 (links. lww.com/WNL/A34) presents the characteristics of various definitions of MCI used in the literature evaluated here. Table e-2 shows the effect on frequency of MCI in the population when less or more stringent MCI criteria were applied.

\section{Analysis}

Twenty Class I studies ${ }^{9,10,12-29}$ and 14 Class II studies ${ }^{30-40, e 1-e 3}$ were identified. Eight of the Class I studies showed that a lower education level was significantly associated with a higher prevalence of MCI. ${ }^{9,10,14,18,21,24,27,28}$ Two of the Class I studies indicated that male sex was associated with the presence of $\mathrm{MCI}^{13,24}$ but other studies found similar baseline prevalence in men and women. ${ }^{14,15,27}$

A random-effects meta-analysis using Class I and II studies confirmed an increased prevalence with cohort age. The allstudies estimate for individuals aged 60-64 years was $6.7 \%$ (95\% confidence interval [CI] 3.4\%-12.7\%, $I^{2} 11.0$ ); for those aged $65-69,8.4 \%$ (95\% CI 5.2\%-13.4\%, $\left.I^{2} 0\right)$; for ages $70-74,10.1 \%$ (95\% CI 7.5\%-13.5\%, $I^{2} 5.2$ ); for ages $75-79,14.8 \%$ (95\% CI 10.1\%-21.1\%, $\left.I^{2} 60.7\right)$; and for ages 80-84, 25.2\% (95\% CI 16.5\%-36.5\%, I I 0) (see table e-3, links.lww.com/WNL/A34).

\section{Conclusions}

MCI is common in older populations, and its prevalence increases with age (high confidence, multiple Class I and Class II studies, consistent meta-analysis) and lower educational level (high confidence, multiple Class I studies).

\section{What is the prognosis for patients diagnosed with $\mathrm{MCl}$ for progression to a diagnosis of dementia, and how does this compare with an age-matched general population?}

\section{Analysis}

Nine Class I studies evaluated prognosis for individuals with MCI, 9,13,19,23,27,e2,e4-e7 all showing an increased risk of progression to dementia when participants with MCI were compared with age-matched participants without MCI. A random-effects meta-analysis demonstrated that the cumulative incidence for the development of dementia in individuals with $\mathrm{MCI} / \mathrm{CIND}$ older than age 65 followed for 2 years was $14.9 \%$ (95\% CI $\left.11.6 \%-19.1 \%, I^{2}=0\right)$. In those with MCI/CIND vs age-matched participants at 2-5 years after, the relative risk (RR) of dementia (all types) was 3.3 (95\% CI 2.5-4.5, $I^{2}=4.9$ ); the $\mathrm{RR}$ of the diagnosis of $\mathrm{AD}$ was 3.0 (95\% CI 2.1-4.8, $I^{2}=17.3$ ).

Reversion to normal cognition in individuals with $\mathrm{MCl}$ Four Class I studies ${ }^{9,19,23, \text { e5 }}$ showed reversion to normal cognition on follow-up in $14.4 \%,{ }^{19} 33.3 \%,{ }^{9} 19 \%,{ }^{23}$ and $38 \%{ }^{\mathrm{e} 5}$ of participants with MCI. However, 2 studies documented increased rates of ultimate conversion to dementia in participants with MCI who reverted to normal cognition, suggesting that individuals who revert remain at a higher risk of progression back to MCI or dementia than individuals who have never received an MCI diagnosis (in these studies, $65 \%{ }^{\mathrm{e} 5}$ and $55 \%$ ultimately converted to dementia $^{\mathrm{e}}$ ).

\section{Conclusions}

Persons with MCI are at higher risk of progressing to dementia than age-matched controls (high confidence, multiple concordant Class I studies, meta-analysis). Persons diagnosed with MCI may remain stable, return to neurologically intact, or progress to dementia (multiple Class I studies, 14.4\%-55.6\% reverting to normal).

\section{What pharmacologic treatments are available for patients diagnosed with $\mathrm{MCl}$, and are these treatments effective on cognitive measures of progression to dementia, excluding other symptomatic effects?}

\section{Analysis}

One Class I study, ${ }^{\mathrm{e} 9} 10$ Class II studies described in 9 publications, ${ }^{\mathrm{e} 10-\mathrm{e} 18}$ and 3 Class III studies ${ }^{\mathrm{e} 19-\mathrm{e} 21}$ addressed pharmacologic treatment of MCI. Table 1 describes the available studies and conclusions for each pharmacologic intervention. Comprehensive descriptions of each study, including effect sizes and CIs, are available in the full-length guideline (links.lww.com/WNL/A125).

\section{What nonpharmacologic treatments are effective for patients diagnosed with $\mathrm{MCl}$ ?}

\section{Analysis}

Two Class II studies were reviewed that used exercise as an intervention in individuals with $\mathrm{MCI},{ }^{\mathrm{e} 22, \mathrm{e} 23}$ and 1 Class $\mathrm{II}^{\mathrm{e} 24}$ and 4 Class III studies ${ }^{\mathrm{e} 25-\mathrm{e} 28}$ investigated the use of various cognitive interventions. Table 2 describes the available studies and conclusions for each nonpharmacologic intervention; details are provided in the full-length guideline (links.lww.com/WNL/A125).

\section{Putting the evidence into clinical context}

Care for persons with cognitive impairment meeting various $\mathrm{MCI}$ criteria continues to evolve, with the area of biomarker research changing particularly rapidly. Even in the context of an evolving field, clinicians can provide high-quality care focusing on counseling, treatment, and comorbidity management. Where clinicians are not proficient in caring for the cognitive or behavioral/psychiatric needs of persons with MCI, referral to appropriate specialists is an important part of the treatment paradigm in line with the following recommendations. 
Table 1 Evidence and conclusions for pharmacologic treatments for mild cognitive impairment (MCI)

\begin{tabular}{|c|c|c|}
\hline Agent & Classification of evidence & Conclusion \\
\hline Donepezil & $\begin{array}{l}3 \text { Class II studies (Petersen } 2005_{1}{ }^{\mathrm{e} 10} \\
\text { Doody } 2009,{ }^{\mathrm{e} 11} \text { Salloway } 2004^{\mathrm{e} 12} \text { ) }\end{array}$ & $\begin{array}{l}\text { In patients with } \mathrm{MCl} \text {, donepezil use over } 3 \text { years is possibly ineffective for reducing the } \\
\text { chances of a progression to possible or probable Alzheimer dementia (low confidence in } \\
\left.\text { the evidence, single Class II study [Petersen } 2005^{\mathrm{e} 10}\right] \text { ). In patients with } \mathrm{MCl} \text {, it is unknown } \\
\text { whether donepezil slows progression on various cognitive scales (very low confidence in } \\
\text { the evidence based on } 2 \text { Class II studies with limited precision and small magnitude of } \\
\text { effect) (Doody } 2009,{ }^{\mathrm{e} 11} \text { Salloway } 2004^{\mathrm{e} 12} \text { ). Study Cls could not exclude an important } \\
\text { effect and the ADAS-Cog change was statistically significant but not clinically meaningful. }\end{array}$ \\
\hline
\end{tabular}

\begin{tabular}{lll}
\hline Galantamine & $\begin{array}{l}\text { 2Class II studies (Winblad 2008, } \\
\text { studies reported in } 1 \text { article) }\end{array}$ & $\begin{array}{l}\text { In patients with } \mathrm{MCl} \text {, galantamine use over } 24 \text { months is probably ineffective for } \\
\text { reducing progression to dementia (moderate confidence in the evidence based on } 2 \\
\text { Class II studies). }\end{array}$
\end{tabular}

\begin{tabular}{|c|c|c|}
\hline Rivastigmine & 1 Class II study (Feldman $2007^{\mathrm{e} 14}$ ) & $\begin{array}{l}\text { In patients with } \mathrm{MCl} \text {, rivastigmine use up to } 48 \text { months is possibly ineffective for reducing } \\
\text { the rate of progression to possible or probable Alzheimer dementia (low confidence in }\end{array}$ \\
\hline
\end{tabular}
the evidence based on a single Class II study).

\begin{tabular}{|c|c|c|}
\hline $\begin{array}{l}\text { Flavonoid- } \\
\text { containing drink }\end{array}$ & 1 Class II study (Desideri $2012^{\mathrm{e} 15}$ ) & $\begin{array}{l}\text { In patients with } \mathrm{MCl} \text {, there is insufficient evidence to support or refute the cognitive } \\
\text { benefits of a drink with high-dose flavonoids (about } 990 \text { mg) on an integrated measure } \\
\text { (cognitive } z \text { score) of overall cognitive function at } 8 \text { weeks (very low confidence in the } \\
\text { evidence based on a single Class II study with Cls including unimportant effects; } \\
\text { evidence of a dose response was also unclear). }\end{array}$ \\
\hline
\end{tabular}

Homocysteine-
lowering B vitamins

In patients with $\mathrm{MCl}$, there is insufficient evidence to support or refute the use of homocysteine-lowering therapies in patients with $\mathrm{MCl}$ (very low confidence in the evidence based on a single Class II study with decreased confidence in the evidence owing to use of a primary endpoint with unclear clinical significance).

Transdermal
nicotine patch

Six months of transdermal nicotine $(15 \mathrm{mg} / \mathrm{d})$ use possibly improves cognitive test performance but not Clinical Global Impression of Change in patients with aMCI who do not smoke (low confidence in the evidence based on 1 Class I study with decreased confidence in the evidence owing to uncertain clinical significance of the outcome of hit reaction time).

\begin{tabular}{|c|c|c|}
\hline Piribedil & 1 Class III study (Nagaraja $2001^{\mathrm{e} 19}$ ) & $\begin{array}{l}\text { Data are insufficient to support or refute an effect of piribedil on cognitive measures in } \\
\mathrm{MCl} \text { (very low confidence in the evidence based on } 1 \text { Class III study). }\end{array}$ \\
\hline Rofecoxib $^{a}$ & 1 Class II study (Thal $2005^{\mathrm{e} 17}$ ) & $\begin{array}{l}\text { Rofecoxib possibly increases the risk of progression to } A D \text { in patients with } \mathrm{MCl} \text { (low } \\
\text { confidence in the evidence based on } 1 \text { Class II study). }\end{array}$ \\
\hline $\begin{array}{l}\text { Tesamorelin } \\
\text { injections }\end{array}$ & 1 Class II study (Baker $2012^{\mathrm{e} 18}$ ) & $\begin{array}{l}\text { In patients with } \mathrm{MCl} \text {, treatment with tesamorelin injections over } 20 \text { weeks is possibly } \\
\text { effective to improve performance on various cognitive measures (low confidence in the } \\
\text { evidence based on } 1 \text { Class II study). }\end{array}$ \\
\hline V0191 & 1 Class III study (Dubois $2012^{\mathrm{e} 20}$ ) & $\begin{array}{l}\text { Data are insufficient to support or refute an effect of V0191 use on ADAS-Cog response } \\
\text { rates in patients with } \mathrm{MCI} \text { (very low confidence in the evidence based on } 1 \text { Class III study). }\end{array}$ \\
\hline Vitamin E & 1 Class II study (Petersen $2005^{\mathrm{e} 10}$ ) & $\begin{array}{l}\text { In patients with } \mathrm{MCl} \text {, use of vitamin E 2,000 IU daily is possibly ineffective for reducing } \\
\text { progression to } \mathrm{AD} \text { (low confidence in the evidence based on a single Class II study). }\end{array}$ \\
\hline $\begin{array}{l}\text { Vitamin E + } \\
\text { vitamin C }\end{array}$ & 1 Class III study (Naeini $2014^{\mathrm{e} 21}$ ) & $\begin{array}{l}\text { In patients with } \mathrm{MCl} \text {, combined use of oral vitamin E } 300 \mathrm{mg} \text { and C } 400 \mathrm{mg} \text { daily over } 12 \\
\text { months is of uncertain efficacy (very low confidence in the evidence based on } 1 \text { Class III } \\
\text { study). }\end{array}$ \\
\hline
\end{tabular}

Abbreviations: AD = Alzheimer disease; ADAS-Cog = Alzheimer's Disease Assessment Scale-cognitive subscale; aMCI = amnestic mild cognitive impairment; $\mathrm{Cl}=$ confidence interval.

References cited here can be found in the e-references (links.Iww.com/WNL/A50) for the guideline summary article.

a Rofecoxib was removed from the market worldwide in September 2004. There are no data on whether other anti-inflammatory medications are effective or harmful in patients with $\mathrm{MCl}$.

${ }^{b}$ It is unclear from this study whether this is effect is sustained beyond 20 weeks.

\section{Practice recommendations}

\section{Section A: Recommendations for assessing for $\mathrm{MCl}$ \\ Recommendation A1}

\section{Rationale}

Appropriate diagnosis of MCI is important because MCI becomes increasingly common as individuals age and is associated with an increased risk of progression to dementia, suggesting that this condition reflects a pathologic disease state rather than normal cognitive aging. Appropriate diagnosis of MCI is important in order to assess for reversible causes of cognitive impairment, to help patients and families understand the cause of their cognitive concerns, and to discuss the prognostic possibilities with the provider so they can plan accordingly, although sharing the diagnosis must be balanced with the potential harm of anxieties from diagnosing a patient with a condition that may not progress. Ascribing cognitive symptoms to normal aging without an assessment for MCI may 
Table 2 Evidence and conclusions for nonpharmacologic treatments for mild cognitive impairment (MCl)

\begin{tabular}{|c|c|c|}
\hline Agent & Classification of evidence & Conclusion \\
\hline Exercise & 2 Class II studies (Nagamatsu 2012, ${ }^{\text {e22 }}$ Suzuki $2013^{\mathrm{e} 23}$ ) & $\begin{array}{l}\text { In patients with } \mathrm{MCl} \text {, treatment with exercise training for } 6 \text { months is likely to } \\
\text { improve cognitive measures (moderate confidence in the evidence based on } \\
2 \text { Class II studies). }\end{array}$ \\
\hline $\begin{array}{l}\text { Cognitive } \\
\text { interventions }\end{array}$ & $\begin{array}{l}1 \text { Class II (Kinsella 2009 }{ }^{\mathrm{e} 24} \text { ) and } 4 \text { Class III studies (Kinsella } \\
2016^{\mathrm{e} 25} \text { Tsolaki 2011, }{ }^{\mathrm{e} 26} \text { Nakatsuka 2015, } \\
2015^{\mathrm{e} 28} \text { ) }\end{array}$ & $\begin{array}{l}\text { There is insufficient evidence to support or refute the use of any individual } \\
\text { cognitive intervention strategy ( } 1 \text { Class II study with results that are not } \\
\text { statistically significant and with suspected imprecision, } 4 \text { Class III studies, } \\
\text { each examining a different cognitive intervention strategy). When various } \\
\text { cognitive interventions are considered as a group, for patients with } \mathrm{MCl} \text {, } \\
\text { cognitive interventions may improve select measures of cognitive function } \\
\text { (low confidence in the evidence based on } 1 \text { Class II study with insufficient } \\
\text { precision [Kinsella } 2009^{\mathrm{e} 24} \text { ], } 1 \text { Class III study showing improvements in } \\
\text { strategy knowledge, internal strategy use, and well-being but not external } \\
\text { strategy or memory [Kinsella } 2016^{\mathrm{e} 25} \text { ], } 1 \text { Class III study [Tsolaki } 2011^{\mathrm{e} 26} \text { ] } \\
\text { showing improvement on multiple cognitive measures, } 1 \text { Class III study } \\
\text { [Nakatsuka } 2015^{\mathrm{e} 27} \text { ] showing improvement on the MMSE but with some } \\
\text { limitations, and } 1 \mathrm{Class} \text { III study [Lam } 2015^{\mathrm{e} 28} \text { ] showing no differences when } \\
\text { all patients with MCI are considered, but with improvements in the } \\
\text { integrated cognitive-physical training groups when considering the ADAS- } \\
\text { Cog, fluency, and recall in patients with single-domain } \mathrm{MCl} \text { and fluency in } \\
\text { patients with multidomain MCI). }\end{array}$ \\
\hline
\end{tabular}

Abbreviations: ADAS-Cog = Alzheimer's Disease Assessment Scale-cognitive subscale; MMSE = Mini-Mental State Examination. References cited here can be found in the e-references (links.Iww.com/WNL/A50) for the guideline summary article.

result in failure to assess for reversible causes of cognitive impairment or to provide patients and families with an accurate diagnosis that may affect life choices, or both. Although subjective cognitive complaints alone are insufficient to diagnose $\mathrm{MCI},{ }^{\mathrm{e} 29}$ such complaints from either patients or their close contacts are core to most major MCI diagnostic criteria, as they may reflect a change in cognitive function. ${ }^{\mathrm{e} 0}$

\section{Recommendation}

For patients for whom the patient or a close contact voices concern about memory or impaired cognition, clinicians should assess for MCI and not assume the concerns are related to normal aging (Level B).

\section{Recommendation A2}

\section{Rationale}

In the United States, the Medicare Annual Wellness Visit requires an assessment to detect cognitive impairment. ${ }^{\text {e31 }}$ Subjective cognitive complaints alone can result in overdiagnosis or underdiagnosis of $\mathrm{MCI}$ and thus are insufficient to screen for MCI. ${ }^{\text {e29 }}$ Clinicians assessing for cognitive impairment should use a brief, validated cognitive assessment instrument in addition to eliciting patient and informant history regarding cognitive concerns.

\section{Recommendation}

When performing a Medicare Annual Wellness Visit, clinicians should not rely on historical report of subjective memory concerns alone when assessing for cognitive impairment (Level B).

\section{Recommendation A3}

\section{Rationale}

When screening or assessing for MCI, validated assessment tools should be used. Various instruments have acceptable diagnostic accuracy for detecting MCI, with no instrument being superior to another. ${ }^{\text {32 }}$ Because brief cognitive assessment instruments are usually calibrated to maximize sensitivity rather than specificity, patients who test positive for MCI should then have further assessment (e.g., more indepth cognitive testing, such as neuropsychological testing with interpretation based on appropriate normative data) to formally assess for this diagnosis. Diagnosis of MCI is based ultimately on a clinical evaluation determining cognitive function and functional status and not solely on a specific test score.

\section{Recommendation}

For patients for whom screening or assessing for MCI is appropriate, clinicians should use validated assessment tools to assess for cognitive impairment (Level B). For patients who test positive for $\mathrm{MCI}$, clinicians should perform a more formal clinical assessment for diagnosis of MCI (Level B).

\section{Recommendation A4}

\section{Rationale}

In the presence of cognitive impairment, clinicians need to distinguish between a diagnosis of $\mathrm{MCI}$ and one of dementia, although the boundary is not always clear. Diagnosing dementia prematurely can lead to negative consequences for patients and families. Only a proportion of patients with MCI will proceed to dementia. In patients with cognitive 
impairment, clinicians must carefully assess for evidence of functional impairment limiting independence in daily activities (e.g., by taking a careful history from the patient and a close contact), a requirement for all dementia diagnoses, to help distinguish between MCI and dementia. With a specific inquiry about functional impairment, clinicians may also identify dementia in patients when patients and family are less forthcoming about functional problems.

\section{Recommendation}

For patients with MCI, clinicians should assess for the presence of functional impairment related to cognition before giving a diagnosis of dementia (Level B).

\section{Recommendation A5}

\section{Rationale}

Diagnoses of MCI and dementia have important implications for patients and families. Appropriate diagnosis is important for informing evaluation for underlying causes, counseling on longterm prognosis, and recommending therapeutic strategies. Clinicians in many disciplines can have experience in caring for individuals with cognitive impairment, including family practice, geriatrics, internal medicine, neurology, psychiatry, and psychology. When clinicians without experience in cognitive impairment identify patients for whom there is a concern of MCI, they should refer these patients to a specialist with experience in cognition for further evaluation.

\section{Recommendation}

For patients suspected to have MCI, clinicians who lack the necessary experience should refer these patients to a specialist with experience in cognition (Level B).

\section{Recommendation A6}

\section{Rationale}

Although MCI is a high-risk state for progression to dementia, some patients with MCI remain stable and some improve. Some cases of MCI are associated with reversible causes of cognitive impairment, including medication side effects, sleep apnea, depression, and other medical conditions. ${ }^{\text {e33 }}$ Patients with MCI should undergo a medical evaluation for MCI risk factors that may be treatable.

\section{Recommendation}

For patients diagnosed with MCI, clinicians should perform a medical evaluation for MCI risk factors that are potentially modifiable (Level B).

\section{Recommendation A7}

\section{Rationale}

Because patients with MCI can improve, remain stable, or progress cognitively, identifying biomarkers that can stratify risk is expected to be particularly important for prognosis. The use of biomarkers in patients with MCI is a rapidly evolving field, ${ }^{\mathrm{e} 4-\mathrm{e} 36}$ but to date, there are no biomarkers clearly shown to predict progression in patients with $\mathrm{MCI}{ }^{\mathrm{e} 37}$

\section{Recommendation $\mathrm{A7a}$}

For patients and families asking about biomarkers in MCI, clinicians should counsel that there are no accepted biomarkers available at this time (Level B).

\section{Recommendation $A 7 b$}

For interested patients, clinicians may discuss the option of biomarker research or refer patients, or both, if feasible, to centers or organizations that can connect patients to this research (e.g., subspecialty centers, Trial Match, ClinicalTrials.gov) (Level C).

\section{Recommendation A8}

\section{Rationale}

Because patients with MCI can improve, remain stable, or progress cognitively over time, patients must be monitored serially for changes in status that could change diagnosis and thus management approach (e.g., treatment, counseling). Although MCI has no approved pharmacologic management, there are US Food and Drug Administration (FDA)approved agents for treatment of Alzheimer dementia, ${ }^{\text {e38-e42 }}$ further emphasizing the importance of assessing for a change in cognitive status over time.

\section{Recommendation}

For patients diagnosed with MCI, clinicians should perform serial assessments over time to monitor for changes in cognitive status (Level B).

\section{Section B: Recommendations for management of $\mathrm{MCl}$}

\section{Recommendation B1}

\section{Rationale}

Some patients with MCI improve or remain stable rather than progress. In addition, some cases of MCI are associated with reversible causes of cognitive impairment, including medication side effects, general medical conditions, sleep disturbance, and depression. ${ }^{\text {e33 }}$ Because these risk factors are treatable and have implications of their own, weaning patients from use of cognitively impairing medications where feasible and treating risk factors that may contribute to cognitive impairment should be the first steps in managing MCI, particularly because symptomatic treatment options are limited for impaired cognition.

\section{Recommendation}

For patients diagnosed with MCI, clinicians should wean patients from medications that can contribute to cognitive impairment (where feasible and medically appropriate) and treat modifiable risk factors that may be contributing (Level B). 


\section{Recommendation B2}

Rationale

There are no FDA-approved medications for the treatment of MCI. Moreover, there are no high-quality, long-term studies identifying pharmacologic or dietary agents that either improve cognition or delay progression in patients with MCI.

\section{Recommendation}

For patients diagnosed with MCI, clinicians should counsel the patients and families that there are no pharmacologic or dietary agents currently shown to have symptomatic cognitive benefit in $\mathrm{MCI}$ and that no medications are FDA-approved for this purpose (Level B).

\section{Recommendation B3}

\section{Rationale}

Studies of cholinesterase inhibitors showed no benefit on cognitive outcomes or reduction in progression from MCI to dementia, although some studies could not exclude an important effect. In addition to lacking efficacy, side effects of cholinesterase inhibitors are common, including gastrointestinal symptoms and cardiac concerns. ${ }^{\text {e43 }}$

\section{Recommendation $\mathrm{B} 3 \mathrm{a}$}

For patients diagnosed with $\mathrm{MCI}$, clinicians may choose not to offer cholinesterase inhibitors (Level B).

\section{Recommendation B3b}

If clinicians choose to offer cholinesterase inhibitors, they must first discuss with patients the fact that this is an off-label prescription not currently backed by empirical evidence (Level A).

\section{Recommendation B4}

Rationale

Clinical trials provide an opportunity for interested patients to participate in identifying or testing new treatment options, which is of particular importance when no pharmacologic options are available.

\section{Recommendation}

For patients diagnosed with MCI who are interested in pharmacologic treatment, clinicians may inform these patients of centers or organizations that can connect patients to clinical trials (e.g., subspecialty centers, Trial Match, ClinicalTrials.gov) (Level C).

\section{Recommendation B5}

\section{Rationale}

Although long-term studies are unavailable, 6-month studies suggest a possible benefit of twice-weekly exercise for cognition in MCI. Exercise also has general health benefits and generally limited risk.

\section{Recommendation}

For patients diagnosed with MCI, clinicians should recommend regular exercise (twice/week) as part of an overall approach to management (Level B).

\section{Recommendation B6}

\section{Rationale}

Because the concept of MCI may be poorly understood or distressing to patients and families, it is important to educate patients and families regarding the diagnosis of $\mathrm{MCI}$ and how it may progress to dementia but also how individuals with $\mathrm{MCI}$ can remain stable or improve. Because MCI may progress to dementia, and particularly because of the lack of effective pharmacologic therapy or any proven methods to reduce the risk of progression of MCI to dementia, it is particularly important to educate patients with MCI regarding their diagnosis and prognosis at the MCI stage while they can still understand the discussion and participate in planning, even though they may or may not progress. Because of the possibility of progression to a dementia state where patients may no longer be able to participate in decision making, patients with MCI should be encouraged to participate in long-term planning, including topics such as advance directives, living wills, power of attorney designations, and finances, which are important irrespective of progression.

\section{Recommendation}

For patients diagnosed with MCI, clinicians should discuss diagnosis and uncertainties regarding prognosis. Clinicians should counsel patients and families to discuss long-term planning topics such as advance directives, driving safety, finances, and estate planning (Level B).

\section{Recommendation B7}

\section{Rationale}

Although there are no treatments for cognitive symptoms in $\mathrm{MCI}$, clinicians need to evaluate for and treat other symptoms that can contribute to quality of life in MCI. Behavioral/psychiatric symptoms are common in $\mathrm{MCI}^{\mathrm{e44}-}$ ${ }^{\mathrm{e}} 46$ and may be associated with greater functional impairment ${ }^{\mathrm{e} 47}$ and an increased risk of progression from MCI to dementia. ${ }^{\mathrm{e} 8, \mathrm{e} 49}$

\section{Recommendation}

Clinicians should assess for behavioral and neuropsychiatric symptoms in MCI and treat with both pharmacologic and nonpharmacologic approaches when indicated (Level B). 


\section{Recommendation B8}

\section{Rationale}

In patients with $\mathrm{MCI}$, cognitive interventions may be beneficial in improving measures of cognitive function. It is good practice to offer nonmedication approaches to care.

\section{Recommendation}

In patients with $\mathrm{MCI}$, clinicians may recommend cognitive interventions (Level C).

\section{Suggestions for future research}

The guideline panel recommends (1) the use of consistent diagnostic criteria for MCI and dementia in clinical trials, to improve the ability to apply and combine results; (2) the inclusion of patient cohorts with specific biomarker data in treatment studies targeted at specific pathologies (e.g., MCI due to $\mathrm{AD})$; (3) the use of outcome measures that are direct measures of clinically meaningful patient outcomes (i.e., development of dementia, reduction of ability to undertake activities of daily living or IADL, patient or caregiver [or both] quality of life measures) or surrogate markers that have previously been shown to have a strong correlation with such measures; (4) standardized reporting of trial design in publications using CONSORT criteria ${ }^{\mathrm{e} 0}$; (5) study of MCI thought to be secondary to $\mathrm{AD}$ and $\mathrm{MCI}$ related to other pathologies (e.g., vascular MCI, MCI related to Lewy body pathology); and (6) further study of early lifestyle and comorbidity modifications and the effects of such changes on the progression of MCI to different dementia subtypes.

\section{Disclaimer}

Clinical practice guidelines, practice advisories, systematic reviews, and other guidance published by the American Academy of Neurology (AAN) and its affiliates are assessments of current scientific and clinical information provided as an educational service. The information (1) should not be considered inclusive of all proper treatments, methods of care, or as a statement of the standard of care; (2) is not continually updated and may not reflect the most recent evidence (new evidence may emerge between the time information is developed and when it is published or read); (3) addresses only the question(s) specifically identified; (4) does not mandate any particular course of medical care; and (5) is not intended to substitute for the independent professional judgment of the treating provider, as the information does not account for individual variation among patients. In all cases, the selected course of action should be considered by the treating provider in the context of treating the individual patient. Use of the information is voluntary. The AAN provides this information on an "as is" basis and makes no warranty, expressed or implied, regarding the information. The AAN specifically disclaims any warranties of merchantability or fitness for a particular use or purpose. The AAN assumes no responsibility for any injury or damage to persons or property arising out of or related to any use of this information or for any errors or omissions.

\section{Conflict of interest}

The American Academy of Neurology (AAN) is committed to producing independent, critical, and truthful clinical practice guidelines (CPGs). Significant efforts are made to minimize the potential for conflicts of interest to influence the recommendations of this CPG. To the extent possible, the AAN keeps separate those who have a financial stake in the success or failure of the products appraised in the CPGs and the developers of the guidelines. Conflict of interest forms were obtained from all authors and reviewed by an oversight committee prior to project initiation. The AAN limits the participation of authors with substantial conflicts of interest. The AAN forbids commercial participation in, or funding of, guideline projects. Drafts of the guideline have been reviewed by at least 3 AAN committees, a network of neurologists, Neurology peer reviewers, and representatives from related fields. The AAN Guideline Author Conflict of Interest Policy can be viewed at aan.com. For complete information on this process, access the 2004 AAN process manual. ${ }^{7}$

\section{Author contributions}

Dr. Petersen: study concept and design, acquisition of data, analysis or interpretation of data, drafting/revising the manuscript, critical revision of the manuscript for important intellectual content, study supervision. Dr. Lopez: study concept and design, analysis or interpretation of data, drafting/revising the manuscript, critical revision of the manuscript for important intellectual content. Dr. Armstrong: analysis or interpretation of data, drafting/revising the manuscript, critical revision of the manuscript for important intellectual content, study supervision. T.S.D. Getchius: study concept and design, study supervision. Dr. Ganguli: study concept and design, analysis or interpretation of data, drafting/revising the manuscript, critical revision of the manuscript for important intellectual content. Dr. Gloss: analysis or interpretation of data, study supervision. Dr. Gronseth: analysis or interpretation of data. Dr. Marson: study concept and design, analysis or interpretation of data, drafting/revising the manuscript, critical revision of the manuscript for important intellectual content. Dr. Pringsheim: analysis and interpretation of data, study supervision. Dr. Day: analysis and interpretation of data, study supervision. Dr. Sager: study concept and design, analysis or interpretation of data, critical revision of the manuscript for important intellectual content. Dr. Stevens: study concept and design, analysis or interpretation of data, drafting/revising the manuscript, critical revision of the manuscript for important intellectual content. Dr. Rae-Grant: analysis or interpretation of data, drafting/revising the manuscript, critical revision of the manuscript for important intellectual content. 


\section{Acknowledgment}

The authors thank Patricia J. Erwin of the Mayo Medical Library for performing the literature searches; Julie Cox, MFA, and Jonathan Dittman, MA, MFA, of the AAN for their work in copyediting the manuscripts and related documents; and Shannon Merillat, MLIS, of the AAN for her work in coordinating the project.

\section{Study funding}

This practice guideline was developed with financial support from the American Academy of Neurology. Authors who serve as AAN subcommittee members, methodologists, or employees, past or present (M.J.A., T.S.D.G., D.G., G.S.G., T.P., G.S.D, A.R.G.), were reimbursed by the AAN for expenses related to travel to subcommittee meetings where drafts of manuscripts were reviewed.

\section{Disclosure}

R. Petersen has served as a consultant for Roche Inc., Merck Inc., Genentech Inc., and Biogen Inc.; receives publishing royalties from Oxford University Press; performs clinical procedures relating to mild cognitive impairment in his clinical neurology practice; and receives research support from the National Institute on Aging of the NIH. O. Lopez has been a consultant for Grifols Inc., Lundbeck, and Raman Technologies and has received grant support from the NIH. M. Armstrong serves on the Level of Evidence editorial board for Neurology ${ }^{\circledR}$ (but is not compensated financially) and serves as an evidence-based medicine methodologist for the American Academy of Neurology (AAN). T. Getchius was an employee of the AAN and has nothing to disclose. M. Ganguli has served on the data safety and monitoring board for Indiana University and on the advisory committee for Biogen Inc. and has received research support from the National Institute on Aging of the NIH. D. Gloss serves as an evidencebased medicine methodologist for the AAN. G. Gronseth serves as associate editor for Neurology, serves on the editorial advisory board for Neurology Now, and is compensated by the AAN for methodologic activities. D. Marson serves as a consultant for and received royalties from Janssen Pharmaceuticals and receives research support from the National Institute on Aging for the NIH. T. Pringsheim has received financial reimbursement for travel to attend the Movement Disorder Society Meeting from Allergan Canada and Teva Canada Innovation and has received research support from Shire Canada Inc. and the Canadian Institutes of Health Research. G. Day received honoraria for serving as faculty at the 2016 AAN annual meeting and holds stock $(>\$ 10,000)$ in ANI Pharmaceuticals (generic manufacturer). M. Sager, J. Stevens, and A. Rae-Grant report no disclosures relevant to the manuscript. Go to Neurology.org/N for full disclosures.

Received February 24, 2017. Accepted in final form September 22, 2017.

\section{References}

1. Winblad B, Palmer K, Kivipelto M, et al. Mild cognitive impairment: beyond controversies, towards a consensus: report of the International Working Group on Mild Cognitive Impairment. J Intern Med 2004;256:240-246.
2. Petersen RC. Mild cognitive impairment as a diagnostic entity. J Intern Med 2004; 256:183-194.

3. Petersen RC, Smith GE, Waring SC, Ivnik RJ, Tangalos EG, Kokmen E. Mild cognitive impairment: clinical characterization and outcome. Arch Neurol 1999;56:303-308.

4. Huey ED, Manly JJ, Tang MX, et al. Course and etiology of dysexecutive MCI in a community sample. Alzheimers Dement 2013;9:632-639.

5. Petersen RC, Stevens JC, Ganguli M, Tangalos EG, Cummings JL, DeKosky ST. Practice parameter: early detection of dementia: mild cognitive impairment (an evidence-based review): report of the Quality Standards Subcommittee of the American Academy of Neurology. Neurology 2001;56:1133-1142.

6. Lyketsos CG, Lopez OL, Jones B, Breitner J, DeKosky ST. A population-based study of the prevalence of neuropsychiatric disturbances in dementia and mild cognitive impairment: results from the Cardiovascular Health Study. JAMA 2002;288: 1425-1483.

7. American Academy of Neurology. Clinical Practice Guideline Process Manual, 2004 ed. [online]. St. Paul: The American Academy of Neurology. Available at: aan.com/ uploadedFiles/Website Library Assets/Documents/2.Clinical_Guidelines/4. About_Guidelines/1.How_Guidelines_Are_Developed/2004\%20AAN\%20Process \%20Manual.pdf. Accessed March 7, 2008.

8. American Academy of Neurology. Clinical Practice Guideline Process Manual, 2011 ed. Available at: aan.com/Guidelines/Home/Development. Accessed April 12, 2012.

9. Ganguli M, Dodge HH, Shen C, DeKosky ST. Mild cognitive impairment, amnestic type: an epidemiologic study. Neurology 2004;63:115-121.

10. Fei M, Qu YC, Wang T, Yin J, Bai JX, Ding QH. Prevalence and distribution of cognitive impairment no dementia (CIND) among the aged population and the analysis of socio-demographic characteristics: the community-based cross-sectional study. Alzheimer Dis Assoc Disord 2009;23:130-138.

11. Bennett DA, Schneider JA, Bienias JL, Evans DA, Wilson RS. Mild cognitive impairment is related to Alzheimer disease pathology and cerebral infarctions. Neurology 2005;64:834-841.

12. Anstey KJ, Cherbuin N, Christensen $\mathrm{H}$, et al. Follow-up of mild cognitive impairment and related disorders over four years in adults in their sixties: the PATH through Life Study. Dement Geriatr Cogn Disord 2008;26:226-233.

13. Di Carlo A, Lamassa M, Baldereschi M, et al. CIND and MCI in the Italian elderly: frequency, vascular risk factors, progression to dementia. Neurology 2007;68: 1909-1916.

14. Hanninen T, Hallikainen M, Tuomainen S, Vanhanen M, Soininen H. Prevalence of mild cognitive impairment: a population-based study in elderly subjects. Acta Neurol Scand 2002;106:148-154.

15. Louis ED, Schupf N, Manly J, Marder K, Tang MX, Mayeux R. Association between mild parkinsonian signs and mild cognitive impairment in a community. Neurology 2005;64:1157-1161.

16. Purser JL, Fillenbaum GG, Wallace RB. Memory complaint is not necessary for diagnosis of mild cognitive impairment and does not predict 10-year trajectories of functional disability, word recall, or short portable mental status questionnaire limitations. J Am Geriatr Soc 2006;54:335-338.

17. Schonknecht P, Pantel J, Kruse A, Schroder J. Prevalence and natural course of agingassociated cognitive decline in a population-based sample of young-old subjects. Am J Psychiatry 2005;162:2071-2077.

18. Artero S, Ancelin ML, Portet F, et al. Risk profiles for mild cognitive impairment and progression to dementia are gender specific. J Neurol Neurosurg Psychiatry 2008;79: 979-984.

19. Boyle PA, Wilson RS, Aggarwal NT, Tang Y, Bennett DA. Mild cognitive impairment: risk of Alzheimer disease and rate of cognitive decline [see comment]. Neurology 2006;67:441-445.

20. Busse A, Hensel A, Guhne U, Angermeyer MC, Riedel-Heller SG. Mild cognitive impairment: long-term course of four clinical subtypes. Neurology 2006;67: 2176-2185.

21. Das SK, Bose P, Biswas A, et al. An epidemiologic study of mild cognitive impairment in Kolkata, India. Neurology 2007;68:2019-2026.

22. Lobo A, Lopez-Anton R, de-la-Camara C, et al. Non-cognitive psychopathological symptoms associated with incident mild cognitive impairment and dementia, Alzheimer's type. Neurotox Res 2008;14:263-272.

23. Lopez OL, Kuller LH, Becker JT, et al. Incidence of dementia in mild cognitive impairment in the Cardiovascular Health Study Cognition Study. Arch Neurol 2007; 64:416-420.

24. Petersen RC, Roberts RO, Knopman DS, et al. Prevalence of mild cognitive impairment is higher in men: The Mayo Clinic Study of Aging. Neurology 2010;75:889-897.

25. Wilson RS, Schneider JA, Arnold SE, Tang Y, Boyle PA, Bennett DA. Olfactory identification and incidence of mild cognitive impairment in older age. Arch Gen Psychiatry 2007;64:802-808.

26. Ganguli M, Chang CC, Snitz BE, Saxton JA, Vanderbilt J, Lee CW. Prevalence of mild cognitive impairment by multiple classifications: the MonongahelaYoughiogheny Healthy Aging Team (MYHAT) project. Am J Geriatr Psychiatry 2010;18:674-683.

27. Lopez OL, Jagust WJ, DeKosky ST, et al. Prevalence and classification of mild cognitive impairment in the Cardiovascular Health Study Cognition Study: part 1. Arch Neurol 2003;60:1385-1389.

28. Shi Z, Zhang Y, Yue W, et al. Prevalence and clinical predictors of cognitive impairment in individuals aged 80 years and older in rural China. Dement Geriatr Cogn Disord 2013;36:171-178.

29. Guaita A, Vaccaro R, Davin A, et al. Influence of socio-demographic features and apolipoprotein E epsilon 4 expression on the prevalence of dementia and cognitive 
impairment in a population of 70-74-year olds: the InveCe.Ab study. Arch Gerontol Geriatr 2015;60:334-343.

30. Anttila T, Helkala E, Viitanen M, et al. Alcohol drinking in middle age and subsequent risk of mild cognitive impairment and dementia in old age: a prospective population based study. BMJ 2004;329:539-542.

31. Barcelos-Ferreira R, Bottino C. Prevalence of amnestic mild cognitive impairment in depressed and nondepressed elderly Brazilian community residents. Alzheimers Dement 2014;10(suppl):P907.

32. De Ronchi D, Palmer K, Pioggiosi P, et al. The combined effect of age, education, and stroke on dementia and cognitive impairment no dementia in the elderly. Dement Geriatr Cogn Disord 2007;24:266-273.

33. Ding $\mathrm{D}$, Zhao $\mathrm{Q}$, Guo $\mathrm{Q}$, et al. Prevalence of mild cognitive impairment in an urban community in China: a cross-sectional analysis of the Shanghai Aging Study. Alzheimers Dement 2015;11:300-309.e302.

34. Gavrila D, Antunez C, Tormo MJ, et al. Prevalence of dementia and cognitive impairment in Southeastern Spain: the Ariadna study. Acta Neurol Scand 2009;120: 300-307.
35. Hilal S, Ikram MK, Saini M, et al. Prevalence of cognitive impairment in Chinese: Epidemiology of Dementia in Singapore study. J Neurol Neurosurg Psychiatry 2013; 84:686-692.

36. Kivipelto M, Helkala E, Hanninen T, et al. Midlife vascular risk factors and late-life mild cognitive impairment: a population-based study. Neurology 2001;56:1683-1689.

37. Lee SB, Kim KW, Youn JC, et al. Prevalence of mild cognitive impairment and its subtypes are influenced by the application of diagnostic criteria: results from the Korean Longitudinal Study on Health and Aging (KLoSHA). Dement Geriatr Cogn Disord 2009;28:23-29.

38. Li X, Ma C, Zhang J, et al; on behalf of the Beijing Ageing Grain Rejuvenation Initiative. Prevalence of and potential risk factors for mild cognitive impairment in community-dwelling residents of Beijing. J Am Geriatr Soc 2013;61:2111-2119.

39. Miyamoto M, Kodama C, Kinoshita T, et al. Dementia and mild cognitive impairment among non-responders to a community survey. J Clin Neurosci 2009;16: 270-276.

40. Olazaran J, Valenti M, Frades B, et al. The Vallecas Project: a cohort to identify early markers and mechanisms of Alzheimer's disease. Front Aging Neurosci 2015;7:181.

\section{What's Your Story? Submit a Video to 2018 Neuro Film Festival}

Do you have a powerful story about the impacts of brain disease on yourself or a loved one? Are you studying neuroscience in school or considering neurology as a career? Do you want to help raise awareness of and funding for critical brain disease research? Or are you simply fascinated by the wonders of the brain? Share your unique story for the 2018 Neuro Film Festival. Video submission deadline is March 2, 2018. Learn more at NeuroFilmFestival.com.

\section{Neurology in the Spotlight at 2018 Annual Meeting in Los Angeles}

Registration is now open for the totally flexible, dynamic 2018 Annual Meeting. We'll be shining the spotlight on neurology and what you need to excel in your career. Look for the latest science, education, and networking you won't find anywhere else when the biggest names in neurology and neuroscience convene in Los Angeles April 21 through 27. Learn more and register now at AAN.com/view/AM18.

\section{Neurology.org/N Offers Important Information to Patients and Their Families}

The Neurology ${ }^{\circledR}$ Patient Page provides:

- A critical review of ground-breaking discoveries in neurologic research that are written especially for patients and their families

- Up-to-date patient information about many neurologic diseases

- Links to additional information resources for neurologic patients

All Neurology Patient Page articles can be easily downloaded and printed, and may be reproduced to distribute for educational purposes. Click on the 'Patients' link on the home page (Neurology.org/ $\mathrm{N}$ ) for a complete index of Patient Pages. 


\section{Neurology}

\section{Practice guideline update summary: Mild cognitive impairment: Report of the Guideline Development, Dissemination, and Implementation Subcommittee of the American Academy of Neurology \\ Ronald C. Petersen, Oscar Lopez, Melissa J. Armstrong, et al. Neurology 2018;90;126-135 Published Online before print December 27, 2017}

DOI 10.1212/WNL.0000000000004826

\section{This information is current as of December 27, 2017}

\section{Updated Information \& Services}

Supplementary Material

\section{References}

Citations

Subspecialty Collections

Permissions \& Licensing

Reprints including high resolution figures, can be found at: http://n.neurology.org/content/90/3/126.full

Supplementary material can be found at: http://n.neurology.org/content/suppl/2018/01/11/WNL.0000000000004 826.DC1

http://n.neurology.org/content/supp1/2018/12/07/WNL.0000000000004 826.DC2

This article cites 38 articles, 13 of which you can access for free at: http://n.neurology.org/content/90/3/126.full\#ref-list-1

This article has been cited by 13 HighWire-hosted articles: http://n.neurology.org/content/90/3/126.full\#\#otherarticles

This article, along with others on similar topics, appears in the following collection(s):

\section{All Cognitive Disorders/Dementia}

http://n.neurology.org/cgi/collection/all_cognitive_disorders_dementia MCI (mild cognitive impairment)

http://n.neurology.org/cgi/collection/mci_mild_cognitive_impairment

Information about reproducing this article in parts (figures,tables) or in its entirety can be found online at:

http://www.neurology.org/about/about_the_journal\#permissions

Information about ordering reprints can be found online:

http://n.neurology.org/subscribers/advertise

Neurology ${ }^{\circledR}$ is the official journal of the American Academy of Neurology. Published continuously since 1951 , it is now a weekly with 48 issues per year. Copyright Copyright (C) 2017 American Academy of Neurology. All rights reserved. Print ISSN: 0028-3878. Online ISSN: 1526-632X.

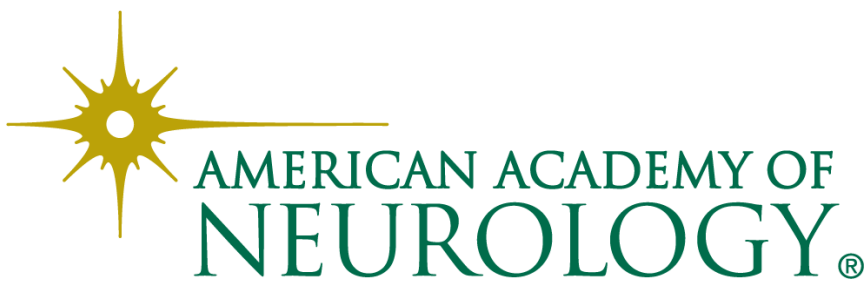

